\title{
Development and Validation of an HPLC Method for Quantification of Filgotinib, a Novel JAK-1 Inhibitor in Mice Plasma: Application to a Pharmacokinetic Study
}

\author{
Authors \\ Ashok Zakkula1, Shobha Pulipati², Sreekanth Dittakavi' ${ }^{1}$, Ram Murthi Bestha', Mohd Zainuddin', Ravi Kumar \\ Trivedi', Ramesh Mullangi'1D
}

\section{Affiliations}

1 Drug Metabolism and Pharmacokinetics, Jubilant Biosys Ltd, Industrial Suburb, Yeshwanthpur, Bangalore, India

2 Department of Pharmacology, Raghavendra Institute of Pharmaceutical Education and Research, Anantapur, A.P. India

\author{
Key words \\ Filgotinib, HPLC, method validation, mice plasma, pharma- \\ cokinetics \\ $\begin{array}{ll}\text { received } & 09.01 .2020 \\ \text { accepted } & 16.03 .2020\end{array}$ \\ Bibliography \\ DOI https://doi.org/10.1055/a-1141-3475 \\ Published online: 14.4 .2020 \\ Drug Res 2020; 70: 233-238 \\ (c) Georg Thieme Verlag KG Stuttgart · New York \\ ISSN 2194-9379 \\ Correspondence \\ Dr. Ramesh Mullangi \\ Drug Metabolism and Pharmacokinetics, Jubilant Biosys Ltd, \\ Industrial Suburb \\ Yeshwanthpur \\ Bangalore 560022 \\ India \\ Tel.:+91-80-66628339, Fax:+91-80-66628333 \\ mullangi.ramesh@jubilantinnovation.com
}

\begin{abstract}
Filgotinib is a selective JAK1 (Janus kinase) inhibitor, filed in Japan for the treatment of rheumatoid arthritis. In this paper, we present the data of development and validation of a highperformance liquid chromatography (HPLC) method for the quantitation of filgotinib in mice plasma as per the FDA regulatory guideline. The method involves the extraction of filgotinib along with internal standard (IS, tofacitinib) from mice plasma $(100 \mu \mathrm{L})$ using ethyl acetate as an extraction solvent. The chromatographic analysis was performed using an isocratic mobile phase comprising $10 \mathrm{mM}$ ammonium acetate $(\mathrm{pH}$ $4.5)$ and acetonitrile $(70: 30, \mathrm{v} / \mathrm{v})$ at a flow-rate of $0.8 \mathrm{~mL} / \mathrm{min}$ on a Hypersil Gold $C_{18}$ column. The UV detection wavelength was set at $\lambda_{\max } 300 \mathrm{~nm}$. Filgotinib and the IS eluted at 5.56 and $4.28 \mathrm{~min}$, respectively with a total run time of $10 \mathrm{~min}$. The calibration curve was linear over a concentration range of 0.05 to $5.00 \mu \mathrm{g} / \mathrm{mL}\left(r^{2}=\geq 0.992\right)$. The intra- and inter-day precision and accuracy results were within the acceptable limits. Results of stability studies indicated that filgotinib was stable on bench-top, in auto-sampler, up to three freeze/thaw cycles and long-term storage at $-80^{\circ} \mathrm{C}$. The validated HPLC method was successfully applied to a pharmacokinetic study in mice.
\end{abstract}

\section{Introduction}

Rheumatoid arthritis affects $1-2 \%$ of the population worldwide. The most popular therapeutic agents to treat rheumatoid arthritis are disease-modifying anti-rheumatoid drugs (DMRADs), which include methotrexate, sulfasalazine, leflunomide etc [1,2]. Due to their low therapeutic benefit and severe side effects, DMARDs cannot be used for long-treatment [2]. On the other hand, biological DMARDs like etanercept, adalimumab etc. showed higher efficacy, however it's use is limited due to parenteral administration, high cost and accessibility etc $[3,4]$. To overcome these drawbacks,
Janus kinase (JAK)/signal transducer and activator of the transcription (STAT) signal pathway has been identified as one of the new therapeutic targets to treat rheumatoid arthritis. JAK-STAT pathway play a critical role in the downstream signaling of cytokines. Inhibition of JAKs is an attractive therapeutic target to treat rheumatoid arthritis [5]. Tofacitinib, is the first pan-JAK inhibitor (JAK1/ JAK3) approved for the treatment of moderate to severe rheumatoid arthritis, however, it showed dose-limiting side effects [6]. Recent findings suggest that selective JAK1 inhibition as a primary 


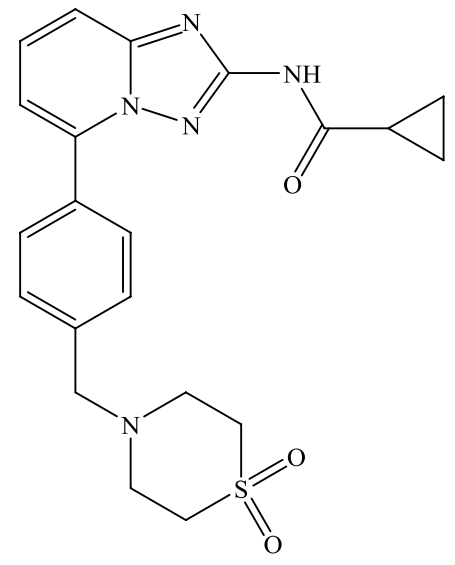<smiles>CC1CCN(C(=O)CC#N)CC1N(C)c1ncnc2[nH]ccc12</smiles>

Tofacitinib (internal standard, IS)

Filgotinib

-Fig. 1 Structural representation of filgotinib and tofacitinib (internal standard, IS).

therapeutic option to treat immune-inflammatory disorders like rheumatoid arthritis, ulcerative colitis, Crohn's disease, psoriasis etc. [7, 8]. Filgotinib ( Fig. 1; GLPG0634), is a selective JAK1 inhibitor $\left(\mathrm{IC}_{50}: 629 \mathrm{nM}\right)$ with 30-fold selectivity over JAK2 and very good efficacy in collagen induced arthritis models for rheumatoid arthritis in mice and rats [9]. In Phase-3 clinical trials, filgotinib was well tolerated and shown efficacy and safety in rheumatoid arthritis patients with 100 or $200 \mathrm{mg}$, once daily dose as a monotherapy or with methotrexate [10]. Several other clinical trials were also conducted with filgotinib in patients suffering from Crohn's disease, ulcerative colitis, ankylosing spondylitis, psoriatic arthritis, Sjögren's syndrome and cutaneous lupus erythematosus etc. Filgotinib is currently being filed in Japan for the treatment of rheumatoid arthritis [11].

So far, two LC-MS/MS (liquid chromatography coupled with tandem mass spectrometry) methods are reported for quantification of filgotinib. Namuor et al. (2015) reported briefly an LC-MS/MS method for the quantification of filgotinib along with its active metabolite for Phase-1 studies plasma samples [12]. In this method authors used solid-phase extraction for plasma samples (enriched with deuterated filgotinib) processing and the lower limit of quantification was $1.00 \mathrm{ng} / \mathrm{mL}$. Other details on chromatography, mass spectrometer conditions and validation parameters were not presented [12]. The generated pharmacokinetic data was used to establish PK-PD (pharmacokinetic-pharamcodynamic) correlation and population pharmacokinetic model $[12,13]$. Very recently, Dixit et al. (2020) reported a validated LC-MS/MS method for quantification of filgotinib. Authors have attained an LLOQ of $0.78 \mathrm{ng} /$ $\mathrm{mL}$ with $50 \mu \mathrm{L}$ rat plasma. Plasma samples were processed using ethyl acetate as an extraction solvent [14].

Although LC-MS/MS is a powerful tool, but its high cost and availability for clinical usage limited its availability. Most of the hospitals, academic institutes and research laboratories use HPLC coupled to an ultra-violet (UV) detector as a common analytical instrument. Post oral administration of filgotinib to rheumatoid arthritis patients, it showed $\sim 100 \mathrm{ng} / \mathrm{mL}$ at $5 \mathrm{~h}$ (post $100 \mathrm{mg}$ dose) and $\sim 85 \mathrm{ng} / \mathrm{mL}$ (post $200 \mathrm{mg}$ dose) at $8 \mathrm{~h}$ [12]. By achieving $50 \mathrm{ng} / \mathrm{mL}$ sensitivity for filgotinib on HPLC-UV, we believe our present method can be used in hospitals for routine therapeutic drug monitoring of filgotinib. Besides, the proposed method can also be used in research laboratories for routine pharmacokinetic and/or toxicokinetic studies samples analysis. In order to ensure the reliability, reproducibility and sensitivity of the method, the developed analytical method was validated for various parameters in accordance with FDA guideline. The validated method was applied to investigate the pharmacokinetics of filgotinib post oral and intravenous administration to mice.

\section{Experimental}

\section{Chemicals and reagents}

Filgotinib (purity: 99.7\%) was obtained from Beijing Yibai Biotechnology Co., Ltd, Beijing, China. Tofacitinib (IS; purity: $98 \%$ ) was purchased from Sigma-Aldrich (St. Louis, USA). Solutol, ethanol and dimethyl sulfoxide (DMSO) were purchased from Sigma-Aldrich, St. Louis, MO, USA. HPLC grade acetonitrile and methanol were purchased from J.T. Baker Avantor, PA, USA. Analytical grade ammonium acetate was purchased from S.D. Fine Chemicals, Mumbai, India. All other chemicals and reagents were of analytical grade and used without further purification. The control mice $\mathrm{K}_{2}$. EDTA plasma was procured from Animal House, Jubilant Biosys, Bangalore.

\section{HPLC operating conditions}

Analysis of filgotinib in plasma samples was performed on a Waters 2695 Alliance HPLC system (Waters, Milford, USA) equipped with performance PLUS inline degasser along with an auto-sampler, column oven and photo diode array (PDA) detector set at $\lambda_{\max } 300 \mathrm{~nm}$. Chromatographic resolution of filgotinib and the IS was achieved by injecting $25 \mu \mathrm{L}$ of the processed sample on a Hypersil Gold $\mathrm{C}_{18}$ column $(250 \times 4.6 \mathrm{~mm}, 5 \mu \mathrm{m}$; Thermo Scientific, USA) maintained at $40 \pm 1{ }^{\circ} \mathrm{C}$ using an isocratic mobile phase consisting $10 \mathrm{mM}$ ammonium acetate, $\mathrm{pH}: 4.5$ (adjusted with acetic acid) and acetonitrile (at a ratio of 70:30, v/v) delivered at a flow-rate of $0.8 \mathrm{~mL} / \mathrm{min}$. 


\section{Preparation of stock solutions for filgotinib and the IS}

For the preparation of calibration curve (CC) and quality control (QC) samples, two primary stock solutions of filgotinib were made at $1.0 \mathrm{mg} / \mathrm{mL}$ in methanol:water $(80: 20, \mathrm{v} / \mathrm{v})$. Similarly, the primary stock solution of the $I S(1.0 \mathrm{mg} / \mathrm{mL})$ was prepared in DMSO. The primary stock solutions of filgotinib and the IS were stored at $-20 \pm 5{ }^{\circ} \mathrm{C}$, which were found to be stable for 50 days. The primary stock solution of the IS was appropriately diluted to get the working stock solution at $500 \mathrm{ng} / \mathrm{mL}$ concentration using methanol:water $(80: 20, v / v)$.

\section{Preparation of calibration curve standards and quality control samples}

The first set of primary stock solution of filgotinib was diluted appropriately and subsequently used to prepare a calibration curve (CC) standards. The calibration standard samples were made by spiking the blank mice plasma $(90 \mu \mathrm{L})$ with each corresponding working solution of filgotinib $(10 \mu \mathrm{L})$ thereby yielding final concentrations of $0.05,0.10,0.50,0.75,1.25,2.50,3.75$ and $5.00 \mu \mathrm{g} / \mathrm{mL}$.

For the determination of precision and accuracy, samples were prepared by spiking blank mice plasma in bulk with the second working stock solution of filgotinib at appropriate concentrations and 100 $\mu \mathrm{L}$ aliquots were distributed into different tubes. The QCs prepared were: $0.05 \mu \mathrm{g} / \mathrm{mL}$ (lower limit of quantification quality control; LLOQ QC), $0.15 \mu \mathrm{g} / \mathrm{mL}$ (low quality control; LQC), $2.25 \mu \mathrm{g} / \mathrm{mL}$ (medium quality control; MQC) and $3.50 \mu \mathrm{g} / \mathrm{mL}$ (high quality control; HQC). All the QCs were stored together at $-80 \pm 10^{\circ} \mathrm{C}$ until analysis.

\section{Sample preparation}

To an aliquot of $100 \mu \mathrm{L}$ mice plasma sample, $1.0 \mathrm{~mL}$ of ethyl acetate was added and vortex mixed for 3 min; followed by centrifugation for $5 \mathrm{~min}$ at $14000 \mathrm{rpm}$ in a refrigerated centrifuge (Eppendorf $5424 \mathrm{R})$ maintained at $5^{\circ} \mathrm{C}$. The organic layer $(850 \mu \mathrm{L})$ was separated and evaporated to dryness at $50^{\circ} \mathrm{C}$ using a gentle stream of nitrogen (Turbovap ${ }^{\circledR}$, Zymark $^{\circledR}$, Kopkinton, MA, USA). The residue was reconstituted in $200 \mu \mathrm{L}$ of the IS solution $(500 \mathrm{ng} / \mathrm{mL})$ and $25 \mu \mathrm{L}$ was injected onto HPLC system for analysis.

\section{Validation procedures}

A full validation according to the US FDA guidance was performed for the quantitation of filgotinib in mice plasma [15].

The selectivity of the proposed method was assessed by evaluating the presence of interfering the peaks at the retention times of filgotinib and the IS in six different batches of blank mice plasma samples. The auto-injector carry over was determined by injecting the highest calibration standard $(5.0 \mu \mathrm{g} / \mathrm{mL})$ followed by injection of mice plasma blank samples. Recovery of filgotinib and the IS was determined by comparing their respective response from QCs (LQC and $\mathrm{HQC}$ ) after the extraction process against their non-extracted samples aqueous solutions. Intra- and inter-day accuracy and precision were determined at four QC levels [LLOQ QC $(0.05 \mu \mathrm{g} / \mathrm{mL})$, LQC $(0.15 \mu \mathrm{g} / \mathrm{mL})$, MQC $(2.25 \mu \mathrm{g} / \mathrm{mL})$ and $\mathrm{HQC}(3.50 \mu \mathrm{g} / \mathrm{mL})]$ along with calibration curve $(0.05-5.00 \mu \mathrm{g} / \mathrm{mL})$. Stability (auto-sampler, bench-top, freeze-thaw and long-term) studies, dilution effect and incurred sample reanalysis were also evaluated as per guideline requirement [15].

\section{Pharmacokinetic study in mice}

Twenty-four male Balb/C mice (weigh range: $27-30 \mathrm{~g}$ ) were procured from Vivo Biotech, Hyderabad, India. Animal study protocols used in this study were approved by the Institutional Animal Ethics Committee, Jubilant Biosys (IAEC/JDC/2019/188R). Mice were housed for a period of seven days having free access to feed and water before the pharmacokinetic studies. Following $4 \mathrm{~h}$ fast (during the fasting period animals had free access to water) mice were divided into two groups having twelve mice in each group. Group1 mice received filgotinib orally by gavage at $50 \mathrm{mg} / \mathrm{Kg}$ [suspension formulation prepared using $0.2 \%$ Tween- 80 and $99.8 \%$ of methyl cellulose $(0.5 \%$ in water); strength: $5.0 \mathrm{mg} / \mathrm{mL}$; dose volume: $10 \mathrm{~mL} / \mathrm{Kg}$ ]. Group-2 mice received filgotinib intravenously [10\% DMSO, $10 \%$ Solutol:absolute alcohol $(1: 1, \mathrm{v} / \mathrm{v})$ and $80 \%$ normal saline; strength: $1.0 \mathrm{mg} / \mathrm{mL}$; dose volume: $10 \mathrm{~mL} / \mathrm{Kg}$ ] at $10 \mathrm{mg} / \mathrm{Kg}$ as a bolus dose. Blood samples $(100 \mu \mathrm{L})$ were collected at pre-determined time points [0.12 (intravenous only), 0.25, 0.5, 1, 2, 4, 8, 10 and $24 \mathrm{~h}$ ] through retro-orbital plexus (using Micropipettes, Drummond Scientific, PA, USA; catalogue number: 1-000-0500) into polypropylene tubes (having $\mathrm{K}_{2}$. EDTA as an anti-coagulant). Sparse sampling technique (three mice per time point and each mouse was bled only twice) was adopted during blood collection so that blood loss from each mouse was kept less than $10 \%$ of the total blood volume. Plasma was harvested by centrifuging the blood using Biofuge (Hereaus, Germany) at $1760 \mathrm{~g}$ for $5 \mathrm{~min}$ and stored frozen at $-80 \pm 10{ }^{\circ} \mathrm{C}$ until analysis. Mice were allowed to access feed $2 \mathrm{~h}$ post-dosing and water ad libitum.

\section{Pharmacokinetic Analysis}

Pharmacokinetic parameters were calculated by a non-compartmental method using Phoenix WinNonlin 8.1 software (Pharsight, Mountain View, CA, USA). Key pharmacokinetic parameters like maximum concentration in plasma $\left(C_{\max }\right)$, time to reach $C_{\max }\left(T_{\max }\right)$, extrapolated plasma drug concentration at time zero following intravenous bolus injection $\left(C_{0}\right)$, area under the curve from time zero to infinity $\left(A \cup C_{0-\infty}\right)$, volume of distribution $(\mathrm{Vd})$, total body clearance $(\mathrm{Cl})$ and half-life $(\mathrm{t} 1 / 2)$ were determined for filgotinib. Absolute oral bioavailability (\%F) was calculated using the relationship

$$
\begin{aligned}
\mathrm{F}= & {\left[\text { Dose }_{(\text {intravenous })} \times \mathrm{AUC}_{(0-\infty) \text { oral }} / \text { Dose }_{(\text {oral) }} \times\right.} \\
& \left.\operatorname{AUC}_{(0-\infty) \text { intravenous }}\right] \times 100
\end{aligned}
$$

\section{Results and Discussion}

\section{Method development and optimization}

Several trials were taken with various columns, mobile phase compositions to select the chromatographic conditions, which will give a good resolution of filgotinib and the IS from the endogenous matrix substances within a suitable run time. Several mobile phases were tried by changing the combination of different organic solvents (acetonitrile and methanol) and buffers (eg: formic acid, ammonium acetate, phosphate buffer etc.) with altered flow-rates (in the range of $0.60-1.20 \mathrm{~mL} / \mathrm{min}$ ). To choose a stationary phase, a variety of columns namely X-Terra Phenyl, Atlantis, Hypersil Gold $\mathrm{C}_{18}$ were evaluated. Our trials revealed that an isocratic mobile phase comprising $10 \mathrm{mM}$ ammonium acetate $(\mathrm{pH} 4.5)$ :acetonitrile 


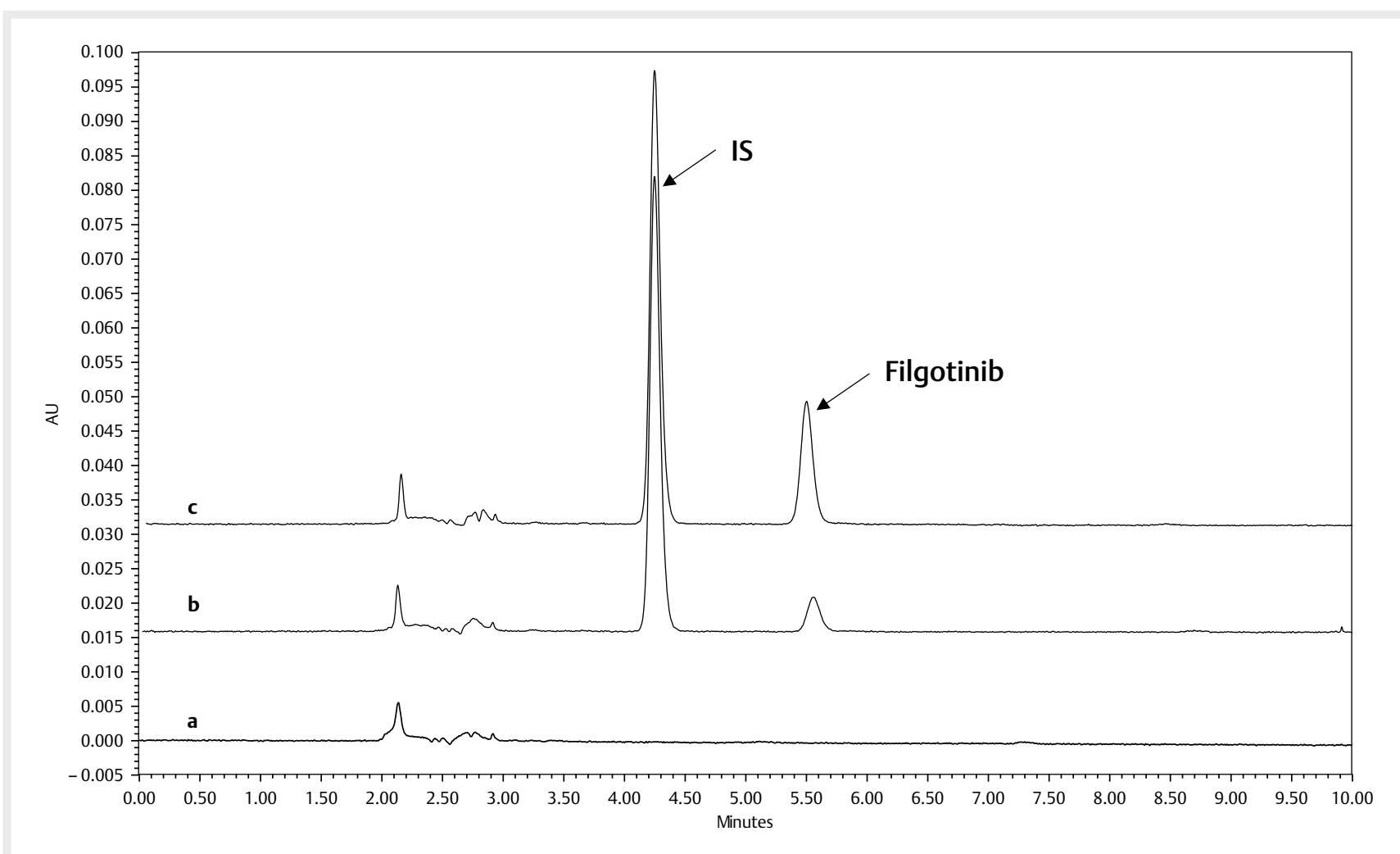

- Fig. 2 Overlay HPLC chromatograms of (a) $25 \mu \mathrm{L}$ injection of a blank mice plasma (b) blank mice plasma spiked with filgotinib at LLOQ (0.05 $\mu \mathrm{g} /$ $\mathrm{mL}$ ) along with the IS (c) 0.5 h plasma sample showing the peak of filgotinib (concentration: $0.75 \mu \mathrm{g} / \mathrm{mL}$ ) following oral administration of filgotinib to mice at $50 \mathrm{mg} / \mathrm{Kg}$.

(70:30, v/v) at a flow-rate of $0.8 \mathrm{~mL} / \mathrm{min}$ on a Hypersil Gold $\mathrm{C}_{18}$ column gave a stable base line with good resolution between filgotinib and the IS. Filgotinib and the IS eluted at 5.56 and $4.28 \mathrm{~min}$, respectively with a total run time of 10 min with no interference of endogenous plasma peaks. The UV detector was set at $\lambda_{\max } 300 \mathrm{~nm}$. Srinivas [16] published an interesting article on usage of commonly prescribed and/or self-medication drugs as choice internal standards with newly developed drug(s) assays especially in BA/BE and therapeutic drug monitoring studies. This is because the commonly used drugs are co-prescribed with new drugs thus limits its utility in wider application [16]. We have evaluated commonly prescribed drugs like phenacetin, warfarin along with first-generation JAK inhibitor, tofacitinib. Under the optimized conditions phenacetin elution overlapped with filgotinib. Though warfarin was found to be suitable but its elution happened $\sim 15 \mathrm{~min}$, this makes each run longer and throughput will be reduced. Subsequently, we found that for the optimized conditions, tofacitinib is a suitable internal standard as it exhibited good resolution, retention time and UV absorbance intensity (UV $\lambda_{\max } 287 \mathrm{~nm}$ ) at the same wave length of filgotinib. Seeing the resolution between the IS ( $4.28 \mathrm{~min}$ ) and filgotinib (5.56 min), we hope this method can be extended as it or with minor modifications (like changing the flow-rate and/or slight change mobile phase composition) to quantitate the active metabolite, which will be more polar and elute just before filgotinib so that the method can be used simultaneous quantification of filgotinib and its active metabolite.

\section{Method validation}

With protein precipitation technique the recovery of filgotinib and the IS was very poor ( $<40 \%$ ). Liquid-liquid extraction with ethyl acetate gave best results in terms of extraction recovery, reproducibility and cleaner samples. The mean \pm S.D recovery of filgotinib at LQC and HQC was $86.38 \pm 3.74$ and $87.98 \pm 1.72 \%$, respectively. The recovery of the IS was $98.43 \pm 3.31 \%$. As shown in $>$ Fig. 2, both filgotinib and the IS peaks were well resolved and no interference at the retention times of filgotinib and IS from the endogenous components of mice plasma. The retention time of filgotinib and the IS was 5.56 and $4.28 \mathrm{~min}$, respectively. The calibration curves $(n=4)$ for filgotinib were observed to be linear in the range of $0.05-$ $5.00 \mu \mathrm{g} / \mathrm{mL}$. A representative equation for the calibration curves is as follows: $y=0.013 x+0.003$. A regression equation with a weighting factor of $1 / X^{2}$ of filogotinib to the IS concentration was found to produce the best fit for the concentration-detector response relationship. The correlation coefficients $\left(r^{2}\right)$ were more than 0.992 , indicating an acceptable linearity of our method. The accuracy observed for the mean of back-calculated concentrations for four calibration curves was within 94.3-102\%; while the precision (\%RE) values ranged from $1.01-4.02 \%$. We did not observe any carryover produced by the highest calibration sample on the following injected mice blank plasma extracted sample for filgotinib. Accuracy and precision data for intra- and inter-day mice plasma samples determined for filgotinib at LLOQ QC $(0.05 \mu \mathrm{g} / \mathrm{mL})$, LQC $(0.15 \mu \mathrm{g} / \mathrm{mL})$, MQC $(2.25 \mu \mathrm{g} / \mathrm{mL})$ and HQC $(3.50 \mu \mathrm{g} / \mathrm{mL})$ are pre- 
- Table 1 Intra- and Inter-day Precision and Accuracy Determination of Filgotinib Quality Controls in Mice Plasma.

\begin{tabular}{|c|c|c|c|c|}
\hline & LLOQ QC $(0.05 \mu \mathrm{g} / \mathrm{mL})$ & LQC $(0.15 \mu \mathrm{g} / \mathrm{mL})$ & MQC $(2.25 \mu \mathrm{g} / \mathrm{mL})$ & $\mathrm{HQC}(3.50 \mu \mathrm{g} / \mathrm{mL})$ \\
\hline \multicolumn{5}{|l|}{ Intra-day $(n=6)$} \\
\hline Mean \pm SD & $0.05 \pm 0.004$ & $0.15 \pm 0.01$ & $2.37 \pm 0.08$ & $3.51 \pm 0.22$ \\
\hline Precision (\% RSD) & 7.56 & 7.26 & 3.43 & 6.12 \\
\hline Accuracy (\% RE) & 1.01 & 1.03 & 1.06 & 1.07 \\
\hline \multicolumn{5}{|l|}{ Inter-day $(n=24)$} \\
\hline Mean \pm S.D & $0.05 \pm 0.003$ & $0.16 \pm 0.01$ & $2.37 \pm 0.15$ & $3.76 \pm 0.25$ \\
\hline Precision (\% RSD) & 6.82 & 7.94 & 6.54 & 6.76 \\
\hline Accuracy (\% RE) & 1.01 & 1.03 & 1.05 & 1.06 \\
\hline
\end{tabular}

- Table 2 Stability Data of Filgotinib Quality Controls in Mice Plasma.

\begin{tabular}{|c|c|c|c|c|c|c|c|c|}
\hline \multirow{2}{*}{$\begin{array}{l}\text { Concentration } \\
\text { spiked }(\mu \mathrm{g} / \mathrm{mL})\end{array}$} & \multicolumn{2}{|c|}{ Bench-top for $6 \mathrm{~h}$} & \multicolumn{2}{|c|}{ Long-term 30 days at $-80^{\circ} \mathrm{C}$} & \multicolumn{2}{|c|}{ Third freeze-thaw cycle } & \multicolumn{2}{|c|}{ Auto-sampler for $24 \mathrm{~h}$} \\
\hline & $\%$ RE & \%RSD & \% RE & \%RSD & \% RE & \%RSD & $\%$ RE & \%RSD \\
\hline $0.15(\mathrm{LQC})$ & 1.05 & 6.32 & 0.98 & 5.08 & 1.02 & 5.59 & 1.08 & 7.65 \\
\hline 3.50 (HQC) & 1.04 & 4.29 & 0.94 & 2.36 & 0.99 & 3.81 & 1.07 & 6.26 \\
\hline
\end{tabular}

> Table 3 Incurred Sample Reanalysis (ISR) data for Filgotinib.

\begin{tabular}{|l|l|l|c|c|}
\hline S. No. & ISR samples & Original concentration $\mathbf{( n g} / \mathbf{m L})$ & ISR concentration $(\mathbf{n g} / \mathbf{m L})$ & \% Change \\
\hline 1 & Filgotinib IV sample-0.12 h & 9305 & 8925 & -4.08 \\
\hline 2 & Filgotinib IV sample-0.12 h & 9580 & 9452 & -1.34 \\
\hline 3 & Filgotinib IV sample-4.00 h & 409 & 425 & 3.91 \\
\hline 4 & Filgotinib IV sample-8.00 h & 177 & 182 & 2.43 \\
\hline 5 & Filgotinib PO sample-0.25 h & 757 & 789 & 4.19 \\
\hline 6 & Filgotinib PO sample-0.50 h & 1611 & 1635 & -49 \\
\hline 7 & Filgotinib PO sample-0.25 h & 490 & 774 & -3.37 \\
\hline 8 & Filgotinib PO sample-0.25 h & 756 & 2.84 \\
\hline
\end{tabular}

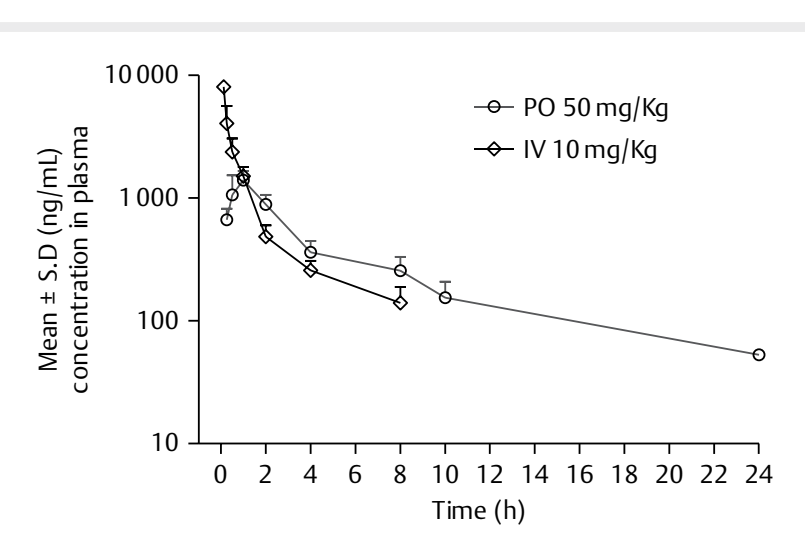

Fig. 3 Mean \pm S.D plasma concentration-time profile of filgotinib following oral and intravenous administration to mice.

sented in $>$ Table 1. The intra- and inter-day precisions (RSD) were within $7.94 \%$, and accuracy (RE) ranged between $1.01-1.07 \%$. The assay values on both the occasions (intra- and inter-day) were found to be within the accepted variable limits indicating that the present method is reproducible, accurate and precise. - Table 2 summa- rizes the results of stability studies conducted for filgotinib in mice plasma. The measured concentrations for filgotinib at LQC $(0.15 \mu \mathrm{g} /$ $\mathrm{mL})$ and $\mathrm{HQC}(3.50 \mu \mathrm{g} / \mathrm{mL})$ deviated within $\pm 15 \%$ of the nominal concentrations in a battery of stability tests namely in-injector $(24 \mathrm{~h})$, bench-top $(6 \mathrm{~h})$, repeated three freeze/thaw cycles and freezer stability at $-80 \pm 10^{\circ} \mathrm{C}$ for 30 days ( $\triangleright$ Table 3 ) supported the stability of filgotinib at various stability conditions. The dilution integrity was confirmed for QC samples that exceeded the upper limit of the calibration curve. The mean accuracy and precision were found to be less than 7.87 and $5.46 \%$, respectively, which show the ability to dilute samples up to a dilution factor of ten in a linear fashion. All the samples selected for ISR met the acceptance criteria. The back-calculated accuracy values ranged between 95.9-104\% from the initial assay results ( $\triangleright$ Table 3 ).

\section{Pharmacokinetic Study}

Plasma samples collected during pharmacokinetic study were thawed at room temperature and processed as mentioned in section "sample preparation". Along with plasma samples, LQC, MQC and HQC samples (made in blank plasma) were assayed in duplicate and were distributed among unknown samples in the analytical run. Plasma samples showed high concentration above the high calibration stand- 
- Table 4 Pharmacokinetic Parameters for Filgotinib following Oral and Intravenous Administration to Mice.

\begin{tabular}{|l|l|l|}
\hline PK parameters & Oral & Intravenous \\
\hline Dose $(\mathrm{mg} / \mathrm{Kg})$ & 50 & 10 \\
\hline $\mathrm{AUC}_{(0-\infty)}(\mu \mathrm{g} \times \mathrm{h} / \mathrm{mL})$ & 8.24 & 6.91 \\
\hline $\mathrm{C}_{\max } / \mathrm{C}_{0}(\mu \mathrm{g} / \mathrm{mL})$ & 1.40 & 10.4 \\
\hline $\mathrm{T}_{\max }(\mathrm{h})$ & 1.00 & - \\
\hline $\mathrm{t}_{1 / 2}(\mathrm{~h})$ & 7.67 & 3.48 \\
\hline $\mathrm{CL}(\mathrm{mL} / \mathrm{min} / \mathrm{Kg})$ & - & 24.1 \\
\hline $\mathrm{Vd}(\mathrm{L} / \mathrm{Kg})$ & - & 7.26 \\
\hline $\mathrm{F}(\%)$ & 23.8 & - \\
\hline
\end{tabular}

ard $(5.00 \mu \mathrm{g} / \mathrm{mL})$ were diluted appropriately with mice blank plasma to bring the concentration within linearity range. The criteria for acceptance of the analytical runs encompassed the following: (i) $\geq 67 \%$ of QC samples should be $\pm 15 \%$ of the nominal concentration value (ii) $\geq 50 \%$ of QC samples per level should be $\pm 15 \%$ of their nominal concentration value [15].

The mean \pm S.D plasma concentrations versus time for filgotinib following oral and intravenous administration to mice are presented in ( $>$ Fig. 3 . The pharmacokinetic parameters are presented in $>$ Table 4. Filgotinib was quantifiable up to 8 and 24 h post intravenous and oral administration to mice. In summary the validated method was sensitive enough to calculate the pharmacokinetic parameters of filgotinib. Post intravenous administration, the $\mathrm{CL}$ and $\mathrm{Vd}$ were found to be $24.1 \mathrm{~mL} / \mathrm{min} / \mathrm{Kg}$ and $7.26 \mathrm{~L} / \mathrm{Kg}$, respectively. The $\mathrm{AUC}_{0-\infty}$ was $6.91 \mu \mathrm{g} \times \mathrm{h} / \mathrm{mL}$. The $\mathrm{t}^{1} / 2$ was $3.48 \mathrm{~h}$. Post oral administration, filgotinib showed highest plasma concentration $\left(C_{\max }: 1.40 \mu \mathrm{g} / \mathrm{mL}\right)$ at $1.00 \mathrm{~h}\left(\mathrm{~T}_{\max }\right)$ indicating slow absorption from gastrointestinal tract. The $t \frac{1}{2}$ by oral route was $7.67 \mathrm{~h}$. The absolute oral bioavailability was $23.8 \%$.

Namour et al. (2019) reported the plasma concentrations of filgotinib in healthy human volunteers and this study was done to select the dose for Phase IIB [12]. In this study, filgotinib was given to volunteers in two Phase I clinical trials in a wide dose range of 10$450 \mathrm{mg}$ by the oral route. The plasma samples obtained from this study were analyzed using an LC-MS/MS method. We have digitalized the reported plasma concentrations versus time plots of filgotinib reported by Namour et al. [12] using Digitizelt (https://www. digitizeit.de; version 2.0.0; accessed on 15 December 2019) and found that across the tested dose range $(10-450 \mathrm{mg})$ filgotinib was quantifiable up to $24 \mathrm{~h}$. However, post oral administration of efficacy doses i. e., 100 or $200 \mathrm{mg}$ (as monotherapy or along with methotrexate) filgotinib showed $\sim 100 \mathrm{ng} / \mathrm{mL}$ at $5 \mathrm{~h}$ (post $100 \mathrm{mg}$ dose) and $\sim 85 \mathrm{ng} / \mathrm{mL}$ (post $200 \mathrm{mg}$ dose) at $8 \mathrm{~h}$ [12]. By achieving $50 \mathrm{ng} / \mathrm{mL}$ sensitivity for filgotinib on HPLC-UV in the present method, we believe our present method can be reliably used in hospitals for routine therapeutic drug monitoring of filgotinib. By increasing the plasma volume for sample processing and injection volume for HPLC analysis, there is a great possibility that our validated HPLCUV can be used to quantify the filgotinib plasma concentration at terminal time points at therapeutic doses.

\section{Conclusion}

A simple reversed-phase HPLC method for determination of filgotinib in mice plasma has been developed and validated. The proposed method is highly specific, accurate, precise and reproducible. All the validation parameters were within the acceptable limits for a bioanalytical method as per regulatory guideline. This method has been successfully applied to a pharmacokinetic study in mice.

\section{Conflict of Interest}

All the authors have no conflict of interest to declare.

References

[1] Buer ]K. A history of the term DMARD. Inflammopharmacology 2015; 23: 163-171

[2] Doan T, Massarotti E. Rheumatoid Arthritis: An overview of new and emerging therapies. J Clin Pharmacol 2005; 45: 751-762

[3] Detert ], Klaus P. Biologic monotherapy in the treatment of rheumatoid arthritis. Biologics 2015; 9: 35-43

[4] Mócsai A, Kovács L, Gergely P. What is the future of targeted therapy in rheumatology: Biologics or small molecules? BMC Med 2014; 12: 43

[5] O'Shea J], Kontzias A, Yamaoko K et al. Janus kinase inhibitors in autoimmune diseases. Ann Rheum Dis 2013; 72: 111-115

[6] Winthrop KL. The emerging safety profile of JAK inhibitors in rheumatic disease. Nat Rev Rheumatol 2017; 13: 234-243

[7] Chough C, Lee S, Joung M et al. Design, Synthesis and Evaluation of (R)-3-(7-(methyl(7H-pyrrolo[2,3-d]pyrimidin-4-yl)amino)-5azaspiro[2.4]heptan-5-yl)-3-oxopropanenitrile as a JAK1-selective inhibitor. Med Chem Comm 2018; 9: 477

[8] O'Shea JJ, Gadina M. Selective janus kinase inhibitors come of age. Nat Rev Rheumatol 2019; 15: 74-75

[9] Van Rompaey L, Galien R, van der Aar EM et al. Preclinical characterization of GLPG0634, a selective inhibitor of JAK1, for the treatment of inflammatory diseases. J Immunol 2013; 191: 3568-3577

[10] Genovese M, Westhovens R, Meuleners L et al. Effect of filgotinib, a selective JAK 1 inhibitor, with and without methotrexate in patients with rheumatoid arthritis: Patient-reported outcomes. Arthritis Res Ther 2018; 20: 57

[11] Pharma Japan (2019) https://pj.jiho.jp/article/240785

[12] Namour F, Diderichsen PM, Cox E et al. Pharmacokinetics and pharmacokinetic/pharmacodynamic modeling of filgotinib (GLPG0634), a selective JAK1 inhibitor, in support of Phase IIB dose selection. Clin Pharmacokinet 2015; 54: 859-874

[13] Srinivas NR. Comment on: Pharmacokinetics and pharmacokinetic/ pharmacodynamic modeling of filgotinib (GLPG0634), a selective JAK1 inhibitor, in support of Phase IIB dose selection. Clin Pharmacokinet 2015; 54: 1293-1295

[14] Dixit A, Kiran V, Gabani BB et al. Validated LC-MS/MS method for quantitation of a selective JAK1 inhibitor, filgotinib in rat plasma and its application to a pharmacokinetics study in rats. Biomed Chromatogr 2020; (accepted)

[15] US DHHS, FDA, CDER, CVM, Guidance for Industry: Bioanalytical Method Validation, U.S Department of Health and Human Services, Food and Drug Administration, Center for Drug Evaluation and Research (CDER), Center for Veterinary Medicine (CV). 2018 Rockville, MD, USA

[16] Srinivas NR. Should commonly prescribed drugs be avoided as internal standard choices in new assays for clinical samples? Bioanalysis. 2016; 8: 607-610 